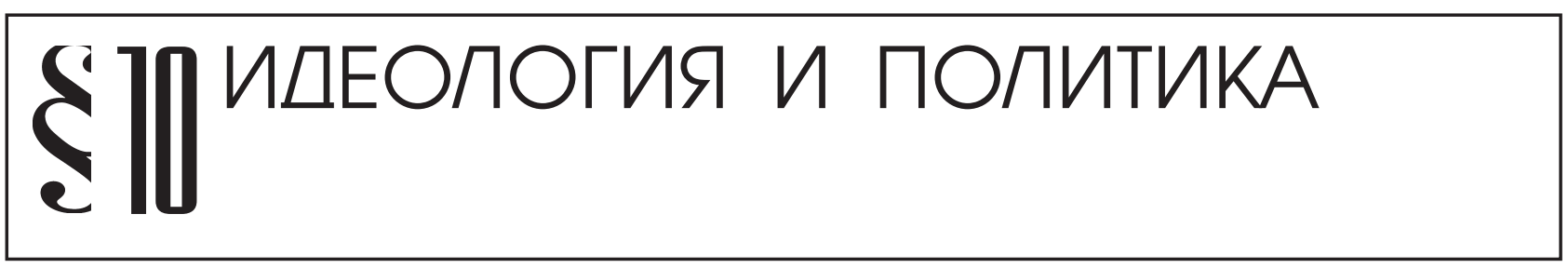

Николаев И.В.

\title{
ВЕРБАЛЬНЫЕ СИМВОЛЫ В СТРУКТУРЕ ПОЛИТИЧЕСКОЙ ИДЕОЛОГИИ
}

\begin{abstract}
Аннотация: Политические идеологии, стремящиеся к максимальному уровню электоральной поддержки, утратили уникальность своих кониепиий идеального политического будущего. Основные идеологические кониепты не имеют четких дефиниций, представляют собой дискурсивный фон театра политических действий. На замену приходит терминология со средней продолжительностью жизни, призванная выполнять мобилизачионные и интеграчионные функиии в условиях конъюнктурных изменений.В исследовании предполагается, что доминирование подобных вербальных символов приводит к окончательной деградации идеологии как устойчивой системы воззрений, и способствует ее упрощению до набора технологических инструментов для поддержания статус-кво или реализачии конкретных проектов. Целью исследования выступает выработка теоретической модели анализа вербальных политических символов, применительно к российскому политическому пространству. Анализ вербальных политических символов базируется на постмарксистской теории дискурса Э. Лаклау и Ш. Муфф, а также на представлениях о "ключевых символах" Г. Лассвелла. Исследование направлено на актуализацию в российской политологии теории "вербальных политических символов", разработанной в американской политической мысли. Вербальный символ, будучи изначально "пустым знаком", наполняется семиотическим содержанием в зависимости от конъюнктурной необходимости, а поэтому нестабилен и изменчив. Идеология, основанная на вербальной символике не имеет устойчивого содержания и выступает коммуникативной мобилизачионной технологией. Теоретическая модель, предложенная в статье, может применяться для анализа современных политических идеологий, предвыборных программ, дискурса политических лидеров и др.
\end{abstract}

Review: Political ideologies that are usually aimed at reaching the highest level of electoral support have lost the uniqueness of their concepts of the ideal political future. The modern ideological concepts have no clear definitions and simply create the discursive background for political actions. Clear definitions are replaced with terms with an average life span that are aimed at performance of mobilizing and integrating functions under the conditions of changing political environment. The author of the article assumes that domination of such 'verbal symbols' lead to final degradation of ideology as a stable system of world views and simplify it to a set of technological tools for maintaining status quo or implementation of particular projects. The purpose of this research is to develop a theoretical model for analyzing verbal political symbols which could be used in Russian political environment. Analysis of verbal political symbols is based on the post-Marxian theory of discourse as introduced by Laclau and Chantal Mouffe as well as the idea about Laswell's 'key symbols'. The research is aimed at attracting attention of Russian political analysts to the theory of 'verbal political symbols' developed by American researchers. Being initially an 'empty sign', verbal symbol acquires a meaning depending on the needs of the political environmentand therefore it is instable and constantly changing. Ideology that is based on verbal symbols does not have a steady content and serves as a communication mobilizing technology. Thetheoreticalmodel offered by the author of the article can be used in analysis of modern political ideologies, election programs, discourse of political leaders and etc.

Ключевые слова: идеология, символизация, вербальный политический символ, конъюнктура, постмарксистская теория дискурса, пустые знаки, лозунг, стабильность, единство, Путин.

Keywords: ideology, symbolization, verbal, political, symbol, environment, post-Marxian theory of discourse, empty signs, motto, stability, unity, Putin. 


\section{Политика и общество 12 (108) • 2013}

$\Pi$ олитическая реальность многозначна и слабо структурирована. Развитие политических отношений привело к дифференциации политических движений и идей, однако условия представительной демократии в современном мире диктуют необходимость ориентации на интерес и предпочтения избирателя, который остается де-юре высшей инстанцией, обладающей правом судить об актуальности и приемлемости политических идеологий. Благодаря этому, идеологии ушли от ортодоксальности и выделения четких границ своих политических предложений, идеологии потеряли важнейший элемент - структурированное представление об идеальном будущем. В условиях стирания границ между политическими идеологиями основные концепты, сформировавшиеся за период становления политической теории, теряют свое смысловое содержание и становятся вербальными символами, пустыми знаками политического дискурса.

В данной работе мы предпримем попытку обосновать тезис о том, что доминирование в идеологическом дискурсе вербальных политических символов создает ситуацию пустоты идеологической концепции, превращает ее в конъюнктурный смысловой конструкт, в котором нельзя выделить инвариантных элементов, сохраняющихся на протяжении продолжительного времени. Вербальные символы выступают в качестве основы идеологического дискурса, что делает его не более чем упражнением в риторике.

Целью данного исследования выступает выявление места и свойств вербальных политических символов в идеологическом дискурсе. Для этого необходимо обратиться к понятию вербального символа, его структуре, а также формам его проявления в дискурсе идеологий. В дальнейшем мы попытаемся проиллюстрировать на примерах из современного и исторического российского опыта, каким образом вербальные символы сказываются на семантическом содержании идеологических концепций.

\section{1.}

Приступая к исследованию вербальных символов в идеологическом пространстве, следует пояснить, что мы имеет в виду под понятием «идеология». Под этой категорией, на наш взгляд следует понимать динамичную систему воззрений и политических взглядов, свойственную социальной группе в определенный период времени, обладающую интегративными и мобилизующими свойствами. Как отмечает К. Мангейм, понятие идеологии связано с пониманием того, что «помимо обычных источников заблуждений существуют ложные структуры сознания; здесь принимается во внимание тот факт, что «действительность», постигнуть которую нам не удается, может быть динамичной, что в одной и той же историко-социальной сфере могут существовать различные структуры ложного сознания, - одни из них опережают «современное» им бытие, другие отстают от него» ${ }^{1}$. Таким образом, в структуре идеологии помимо традиционных представлений и идей присутствуют и изменчивые технологические элементы, такие как политические символы.

В дискурсе идеологии как коммуникативном пространстве присутствуют различные виды знаковых и семиотических структур, значительную долю среди них занимают символы. Как пишет С.П. Поцелуев, «символ выступает незаменимым средством интеграции и мобилизации человеческих коллективов. Символы всегда привлекаются в том случае, когда нужно выразить силу единства и сплоченности социального союза, его коллективные представления» ${ }^{2}$. Символическая коммуникация выполняет ключевые идеологические функции интеграции и мобилизации к политическому действию. Вспомним хотя бы концепт «светлое коммунистическое будущее» или «свободу, равенство и братство» в революционных движениях. «Безусловно, обычный человек, - обращает внимание Г. Лассвелл, - проявляет лишь эпизодический интерес к тем тонкостям, которыми занимаются философы или законодатели и даже многие политические лидеры. Тем не менее, существует некий общий знаменатель между высказываниями обычного человека и мыслителя или политика. Все они используют ключевые символы» ${ }^{3}$.

Для обоснования потенциала символизации вербальных единиц в идеологическом пространстве обратимся к постмарксистской теории дискурса, пред-

\footnotetext{
${ }^{1}$ Мангейм К. Идеология и утопия [Электронный ресурс]. URL: http://socialistica.lenin.ru/txt/m/manheim_1.htm] (дата обращения: 20.11.2013.).

2 Поиелуев С.П. Символическая политика: констелляция понятий для подхода к проблеме // Политические исследования. - 1999. - № 5. - С. 64.

3 Лассвелл Г. Язык власти [Электронный ресурс]. URL: http://philology.ru/linguistics1/lasswell-06.htm (дата обращение: 20.11.2013.).
} 
ставленной в работах Э. Лаклау и Ш. Муфф4 ${ }^{4}$ Следуя за установкой социального конструктивизма, они утверждают, что мир наполняется смыслами только опосредованно языком: то, что не означено языком, не существует. «Завершенная структура, как и «общество», это лишь то, что мы представляем в своем воображении, чтобы сделать наши действия осмысленными» ${ }^{5}$. При этом символическое наполнение общества не является его целостным отражением, а представляет собой только частные символы. Доминирование символических элементов ограничено присутствием Другого, при этом его отрицание является показателем общности, которая обеспечивается не более, чем «гегемонистской универсальностью».

В теории постмарксизма Э. Лаклау и Ш. Муфф общество является пространством перманентной борьбы за дискурсивную гегемонию, то есть за право означивания. По мнению исследователей, политический дискурс состоит из трех видов знаков:

- моменты, зафиксированные и содержательные знаки благодаря наличию антагонистического понятия;

- элементы, которые не имеют четко определенного значения и потенциально могут разрушить дискурсивную систему;

- у узловые точки - ключевые знаки социального пространства. «Узловые точки - это привилегированные знаки, вокруг которых организуется дискурс. Но эти знаки сами по себе «пусты»» ${ }^{6}$. Именно за придание значения этим знакам борются различные дискурсы. Это символическая война и представляет собой политику.

Подобные узловые точки социальной реальности, на наш взгляд, могут являться базисом для формирования вербальных политических символов, так как они обладают общей с ними характеристикой - отсутствием содержательного наполнения. Термины политиче-

\section{«Стабильность»}

(отсутствие кардинальных перемен, состояние покоя системы) ского и околополитического характера захватываются и эксплуатируются идеологическим дискурсом или его подструктурами в лице дискурса власти, бюрократии или партии. Наделение идеологическим смыслом происходит путем насыщения уже существующего слова специфическими ассоциациями, необходимыми субъектам формирования подобных символов. Происходит наслоение смыслов.

2.

Важно отметить, что наделение идеологическим смыслом происходит на краткосрочный период, так как является исключительно технологическим актом, нацеленным на поддержание должного уровня мобилизации общества или сглаживание социальных конфликтов. Рассмотрим на примере из российского опыта. Вербальный символ «стабильность» и связанные с ним формы («стабилизация», «стабильный...») был выдвинут в начале 2000-х годов с претензией на главную политическую ценность в идеологии правящей партии «Единая Россия». Этот концепт не является искомым политическим термином и до этого использовался исключительно как инструментальный, но при президентстве В.В. Путина он становится символом возрождения страны и используется в качестве ярлыка в определении принадлежности к государственной идеологии.

Использование символа - это способ расширения смысла, преодоления границ. Как пишет А.Ф. Лосев, символ - «идейная, образная или идейно-образная структура, содержащая в себе указания на те или иные, отличные от нее предметы, для которых она является обобщением и неразвернутым знаком» ${ }^{7}$. То есть в случае с вербальным символом слово выступает техническим материалом для создания на его основе насыщенного образа.

\section{«Стабильность» => (отказ от серьезных реформ, ради процветания общества)}

\footnotetext{
${ }^{4}$ Laclau E., Mouffe Ch. Hegemony and Socialist Strategy: Towards a Radical Democratic Politics. - London: Verso, 2001. - 240 p.

${ }_{5}^{5}$ Йоргенсен М.В., Филлипс Л.Дж. Дискурс-анализ. Теория и метод / Пер. с англ. - 2-е изд., испр. - Харьков: Изд-во «Гуманитарный центр», 2008. - С. 78.

${ }^{6}$ Там же. С. 60.
}

Непосредственное значение слова есть только незначительная часть смыслового потенциала вербального символа. Многозначность вербальной единицы ${ }^{7}$ Лосев А. Ф. Символ // Философская энциклопедия: т. 5. -
М.: Наука, 1965. - С. 10. 


\section{Политика и общество 12 (108) • 2013}

не вызывает единой эмоциональной реакции реципиентов, необходимой для идеологического дискурса. Поэтому наполняя пустой знак новым смыслом (или дополняя новыми элементами старый) идеология формирует новый концепт, специфический для данной временной и пространственной ситуации.

Таким образом, процесс формирования плеяды вербальных символов дискурса идеологии представляет собой борьбу за означивание пустых знаков («узловых точек»). Стремление к дискурсивной гегемонии («частная социальная сила начинает представлять тотальность, радикально несводимую к ней» ${ }^{8}$ ) обосновывает активное продуцирование вербальных символов идеологическими движениями в публичном политическом пространстве. Это в большей степени касается доминирующей силы (у «Единой России» появились слова-символы «модернизация», «инновации», «вертикаль власти», «деверсификация», «транспарентность» и многие другие). В то время как движения-меньшинства вынуждены сконцентрировать свои силы на сохранении присутствующих в публичном дискурсе вербальных символов, созданных их идеологией, а также на сопротивление попыткам «захвата» этих слов доминирующей идеологией. Так, российские коммунисты вынуждены отстаивать свои права на «власть народа», «социальную справедливость», «человека труда» и т.п.

Логично предположить, что идеологический вербальный символ использует для манипулятивных целей не только семиотическое содержание, но и на определенном этапе популяризации еще и звучание, и графическое отображение. Предлагаем вывести элементарную структуру слова-символа. Несмотря на то, что символ представляется целостным, немаловажную роль играют и его компоненты. Наравне с 1). когнитивной (смысловой) составляющей в конструировании реальности участвуют и 2). аудиальная (звук), и 3). грамматическая (специфический набор морфем, форма слова). Так, вербальный символ «единство», возникший в конце 90-х годов в среде правящей элиты, со временем настолько погрузился в идеологический омут партии власти, что даже упоминание этого слова в мобилизационных текстах (обращениях, публичных речах лозунгах и слоганах) стало признаком

\footnotetext{
${ }^{8}$ Discourse theory and political analysis: identities, hegemonies, and social change / Edited by Howarth D., Norval A., Stavrakakis Y. - Manchester; N. Y.: Manchester University Press, 2000. - P. 55.
}

причастности источника этого текста к партии «Единая Россия». Примечателен пример фильма «Ярослав. Тысячу лет назад» (РФ, 2010 г., режиссер Дмитрий Коробкин). Главному герою приписаны слова, практически повторяющие предвыборный лозунг правящей партии: «В единстве наша сила!», за тем исключением, что он не предлагает будущим жителям Ярославля вступать в ряды Единой России. «Не только язык или лексика, - утверждает Э. Сепир, - но даже и внешние формы его письменной фиксации могут приобретать значение символов сентиментального или социального различия» ${ }^{9}$. Аудио-визуальное отображение слова (номинат) используется на каждом шагу и является наименее осознанной формой приверженности словам-символам.

Не в любом вербальном символе должны присутствовать все манипулятивные компоненты структуры. Большинство слов-символов, возникающих для реализации конкретного проекта и продолжительность жизни которых невелика, не приобретают символически насыщенного аудиального и визуального отображения. «Символ может быть выражен в синкретической словесно-зрительной форме, - пишет Ю.М. Лотман, - которая, с одной стороны, проецируется в плоскости различных текстов, а с другой, трансформируется под обратным влиянием текстов» ${ }^{10}$. Подобными вербальными символами стали, к примеру, медведевские «модернизация» и «гаджеты», недолгое время бывшие концентрацией идеологического дискурса российской власти, но с возвращением Путина в Кремль утратившие свой символический контент.

3.

Очевидно, что занятые соответствующими смыслами вербальные символы выступают рамками дискурсивных практик идеологических движений и задают форму (но не содержание) публичных выступлений, политических лозунгов, предвыборных программ и даже официальных документов. При этом наиболее яркое проявление вербальная символика получает в формате лозунгов. В этом отношении примечательны примеры из опыта Коммунистической партии России, которая продолжая традиции КПСС, по-прежнему,

\footnotetext{
${ }_{9}^{9}$ Сепир Э. Язык // Избранные труды по языкознанию и культурологии. . - М.: Прогресс, 1993. - С. 245.

10 Лотман Ю.М. Символ в системе культуры // Избранные статьи. Т. 1. - Таллин: Александра, 1992. - С. 197.
} 
несмотря на меняющиемся социальные условия, использует вербальную символику советского периода. Стремление сохранить то, что пока не захвачено другими политическими силами, обусловливает приверженность коммунистов лозунгам, апеллирующим к «Ленину», «Великому Октябрю», «народу», «труду», «партии» и т.п.

«Идеям Ленина - жить!»"11

«Великий Октябрь - не отменить!»

«Даёиь советское народовластие!»

«Антинародное правительство - в отставку!»

«Программа партии - программа народа.»

Антисимволом для российских коммунистов выступает партия власти, капитализм, бюрократия, также получающие символическое наполнение в дискурсе КПРФ:

«Министров-капиталистов на стройки Крайнего Севера!»

«26 апреля выбираем не залётного хищуника, а народного зашитника!»

Логично предположить, что подобный консерватизм в символической политике КПРФ обусловлен условиями доминирования одной идеологической структуры, отсутствием свободного пространства для пропаганды и нежеланием допустить символической конфронтации. Вербальная символика российских коммунистов хоть и представляется единой, используется ситуативно и в качестве ответа на агрессивную дискурсивную политику других идеологических течений.

Примечательно, что подобные «нападки» производятся не только единороссами, но и родственной по идеологическому контенту «Справедливой Россией», предпринимающей попытки перехватить вербальные конструкты «справедливость», «человек труда», а также антисимвол «монополисты» и др.:

Защчитим права человека труда!

За пустые канистры мочи монополистов!

Спецификой российского политического пространства является символизация собственных имен объектов и политических лидеров. Данная стратегия свойственна, в первую очередь, представителям правящей партии. Если у КПСС был Ленин («Ленин и теперь живее всех живых!») или Сталин («Спасибо то-

\footnotetext{
11 Здесь и далее примеры политических лозунгов цитируются по: Лозунги политических партий [Электронный ресурс]. URL: http://yavibral.ru/index.php?news_id=13\&page=4 (дата обращения: 20.11.13.).
}

варищу Сталину за наше счастливое детство!»), то в современной России символическим становится имя В.В. Путина («План Путина - будущее России!», «Всё путём!» и т.д.).

\section{$* * *$}

Подводя итог размышлениям, следует отметить, что вербальный символ в идеологическом пространстве представляет собой узловой знак политической реальности, поглощенный определенным идеологическим дискурсом и насыщенный подверженным конъюнктурным изменениям смыслом. В контексте конструирования действительности содержательная сторона слов-символов вторична по отношению к форме. Создание вербального символа представляется в виде наслоения побочных смыслов и ассоциаций на знак и его искомое значение, которое постепенно стирается, а знак теряет свой первоначальный смысл, т. е. становится пустым. Идеологический дискурс, распространяя свою гегемонию, захватывает данный знак и насыщает его тем контекстуальным значением, которое необходимо акторам политической коммуникации. Слово-символ становится элементом политической стратегии. На основе совокупности вербальных символов строится политическая идеология в варианте, приемлемом к ситуации «здесь и сейчас», за счет них же этот вариант может эволюционировать и меняться в зависимости от требований обстоятельств.

\section{Библиография:}

1. Мангейм К. Идеология и утопия [Электронный pecypc]. URL: http://socialistica.lenin.ru/txt/m/manheim_1.htm] (дата обращения: 20.11.2013.).

2. Поцелуев С.П. Символическая политика: констелляция понятий для подхода к проблеме // Политические исследования.-1999.-№ 5.-С. 64.

3. Лассвелл Г. Язык власти [Электронный ресурс]. URL: http://philology.ru/linguistics1/lasswell-06. htm (дата обращение: 20.11.2013.).

4. Laclau E., Mouffe Ch. Hegemony and Socialist Strategy: Towards a Radical Democratic Politics.-London: Verso, 2001.-240 p.

5. Йоргенсен М.В., Филлипс Л.Дж. Дискурс-анализ. Теория и метод / Пер. с англ. - 2-е изд., испр. Харьков: Изд-во «Гуманитарный центр», 2008.C. 78 . 


\section{Политика и общество 12 (108) • 2013}

6. Йоргенсен М.В., Филлипс Л.Дж. Дискурс-анализ. Теория и метод / Пер. с англ. - 2-е изд., испр. - Харьков: Изд-во «Гуманитарный центр», 2008. - С. 60.

7. Лосев А. Ф. Символ // Философская энциклопедия: т. 5. - М.: Наука, 1965.-С. 10.

8. Discourse theory and political analysis: identities, hegemonies, and social change / Edited by Howarth D., Norval A., Stavrakakis Y. - Manchester; N. Y.: Manchester University Press, 2000. - P. 55.

9. СепирЭ. Язык// Избранные труды по языкознанию и культурологии. . - М.: Прогресс, 1993.-С. 245.

10. Лотман Ю.М. Символ в системе культуры // Избранные статьи. Т. 1. - Таллин: Александра, 1992. - С. 197.

11. Лозунги политических партий [Электронный pecypc]. URL: http://yavibral.ru/index.php?news_ $\mathrm{id}=13$ \&page $=4$ (дата обращения: 20.11.13.)

\section{References (transliteration):}

1. Mangeim K. Ideologiya i utopiya [Elektronnyi resurs]. URL: http://socialistica.lenin.ru/txt/m/manheim_1.htm] (data obrashcheniya: 20.11.2013.).
2. Potseluev S.P. Simvolicheskaya politika: konstellyatsiya ponyatii dlya podkhoda $\mathrm{k}$ probleme // Politicheskie issledovaniya. - 1999. - № 5. - S. 64.

3. Lassvell G. Yazyk vlasti [Elektronnyi resurs]. URL: http://philology.ru/linguistics 1/lasswell-06. htm (data obrashchenie: 20.11.2013.).

4. Laclau E., Mouffe Ch. Hegemony and Socialist Strategy: Towards a Radical Democratic Politics.London: Verso, 2001.-240 p.

5. Iorgensen M.V., Fillips L.Dzh. Diskurs-analiz. Teoriya i metod / Per. s angl. - 2-e izd., ispr. Khar'kov: Izd-vo «Gumanitarnyi tsentr», 2008. S. 78 .

6. Iorgensen M.V., Fillips L.Dzh. Diskurs-analiz. Teoriya i metod / Per. s angl. - 2-e izd., ispr. - Khar'kov: Izd-vo «Gumanitarnyi tsentr», 2008. - S. 60.

7. Losev A. F. Simvol // Filosofskaya entsiklopediya: t. 5.-M.: Nauka, 1965.-S. 10.

8. Sepir E. Yazyk // Izbrannye trudy po yazykoznaniyu i kul'turologii. . - M.: Progress, 1993. - S. 245.

9. Lotman Yu.M. Simvol v sisteme kul'tury // Izbrannye stat'i. T. 1.-Tallin: Aleksandra, 1992. S. 197. 